MATEC Web of Conferences 11,01026 (2014)

DOI: $10.1051 /$ matecconf / 20141101026

(C) Owned by the authors, published by EDP Sciences, 2014

\title{
Using New Coating Materials for Corrosion Prevention of Reinforced Concrete
}

\author{
Ahmed. ELSHAMI ${ }^{1}$, A.H.ALI \\ ${ }^{1}$ Lecturer at Housing \& Building National Research Centre \\ 87 El-Tahrir St., Dokki, Giza, Egypt \\ email:materialhnbrc@yahoo.com \\ http://www.hbrc.edu.eg, +201099978795
}

\begin{abstract}
Deterioration of reinforcing concrete structures is a common problem among all the Mediterranean countries. To protect steel from corrosion, cobalt oxide with zinc oxide were successfully deposited on silica and alumina layer according to Core-shell theory. This theory based on depositing a surface layer of expensive efficient anticorrosive coating on a cheap extender expressing the bulk. The combination of both core and shell compounds led to the production of new coating with improved properties different from each of its individual components. These improved properties lead to change in the efficiency of protection properties of coating films containing these new coating. The objective of the present work is to prepare a new ecologically friendly natural and inorganic coating of Egyptian mix (kaolin and ceramic waste) and zinc phosphate as corrosion inhibitors based on the solid-solid interaction to protect steel from corrosion in buildings construction. The results revealed that these new coating gives the best results in protecting steel substrates from corrosion especial in aggressive environment.
\end{abstract}

\section{Introduction}

The objective of the present work is to prepare the kind of new coating which prevents iron rust; this rust causes corrosion of bodies fabricated of iron like reinforced steel in buildings construction, cars, ships and others. Which is a natural material prepared chemically of kaolin and ceramic waste but after many studies have proven the coating role as corrosion inhibitor, which is no longer, confined to add color, but many researchs [1]discovered important functions such as protecting metals from corrosion when used in the concrete industry. It is used as pigment for coating due to its superior stability, excellent heat and chemical resistance, easy to disperse, high tinting strength and a non-migratory excellent hiding power[2].

The comparison between a new ecologically friendly natural coating, inorganic coating and steel without coating was done using accelerated laboratory test on blended cement concrete (BCC) in sea water and pore solution by electrochemical impedance spectroscopy to enhance its capability to conduct work on: pore solution, concrete and analysis, corrosion assessment using the linear polarization resistance method, thus preventing or minimizing steel corrosion.
Environmental and economical benefits from performing this study are, reducing the need to build new buildings, Saving the raw natural materials resources,

Thermal stability this coating, Easy to clean surface, anti-skid, Anti-fogging, Anti-fouling, Antigraffiti properties, better thermal and electrical conductivity. Egyptian mix (kaolin and ceramic waste) can also improve coatings by significantly extending the product life, improving opacity, gloss, colours and viscosity. Egyptian mix is particularly useful as a partial replacement for $\mathrm{TiO}_{2}$ pigment [3].

kaolin and ceramic waste acts on both anodic and cathodic sites and they reduce the corrosion rate without a significant change in the corrosion potential, generally by surface adsorption over the surface of the steel in contact with cobalt and zinc aluminate and consequently forming a thin protective layer[4].

\section{Experimental Programs}

This paper presents two experimental studies to show the effectiveness of kaolin and ceramic waste on concrete behaviour and reinforced concrete protection. 


\subsection{Material and composition of mixture.}

All the employed pigments, extenders, resins, solvents, additives and chemicals were products of different local and international companies. Helwan Portland Cement Co (H.P.C.C.) and Egyptian mix kaolin and ceramic waste $(60 \%$ kaolin and $40 \%$ ceramic waste) used. The chemical composition of H.P.C.C and Egyptian mix is represented in Table 1.

Table 1. Chemical compositions of cement and Egyptian mix.

\begin{tabular}{|c|c|c|c|}
\hline \multirow{2}{*}{$\begin{array}{c}\text { Composition } \\
\text { (\% of mass) }\end{array}$} & \multirow{2}{*}{ H.P.C.C } & \multicolumn{2}{|c|}{ Egyptian mix } \\
\cline { 3 - 4 } & & Kaolin & $\begin{array}{c}\text { Ceramic } \\
\text { waste }\end{array}$ \\
\hline $\mathrm{CaO}$ & 63.38 & 2.68 & 5.05 \\
\hline $\mathrm{SiO}_{2}$ & 20.75 & 52.24 & 61.95 \\
\hline $\mathrm{Al}_{2} \mathrm{O}_{3}$ & 4.39 & 30.41 & 19.64 \\
\hline $\mathrm{Fe}_{2} \mathrm{O}_{3}$ & 3.28 & 0.33 & 7.42 \\
\hline $\mathrm{MgO}^{2}$ & 1,83 & 0.81 & 0.83 \\
\hline $\mathrm{SO}_{3}$ & 2,79 & 0.54 & 0.35 \\
\hline $\mathrm{Na}_{2} \mathrm{O}$ & 0,24 & 0.12 & 0.19 \\
\hline $\mathrm{K}_{2} \mathrm{O}$ & 0,22 & 0.08 & 1.00 \\
\hline $\mathrm{TiO}_{2}$ & 0.10 & 1.45 & 1.11 \\
\hline $\mathrm{P}_{2} \mathrm{O}_{5}$ & 3,01 & 0.53 & 0.17 \\
\hline $\mathrm{L}$ O.I & 0,62 & 11.35 & 0.37 \\
\hline Blaine $\left(\mathrm{cm}^{2} / \mathrm{g}\right)$ & 3860 & 4320 & 4000 \\
\hline
\end{tabular}

\subsection{Test procedures on concrete}

\subsubsection{Mechanical tests on concrete}

For mechanical tests, one type of blended cement concrete (BCC) has been considered. Due to its high affinity to steel, it is also able to displace chloride ions from the metal surface to protect concrete from chloride induced corrosion. Helwan Portland Cement Co (H.P.C.C.) was used to prepare (BCC) by mixing Portland cement with Egyptian mix. The substitution rate of Portland cement with Egyptian mix was 30\%. Natural gravel medium $(4 / 12 \mathrm{~mm})$ and coarse $(12 / 20 \mathrm{~mm})$ aggregates as well as natural sand $(0 / 4 \mathrm{~mm})$ were employed for concrete preparation. Three $110 \times 220 \mathrm{~mm}$ cylindrical samples for compressive strength were prepared from a single batch for each age. The concrete mixtures were cast in plastic of polypropylene moulds and compacted using a mechanical vibrator.

The specimens were stored in a fog room maintained at $20^{\circ} \mathrm{C}$ and $95 \%( \pm 5 \%)$ relative humidity $(\mathrm{RH})$ for $24 \mathrm{~h}$ after casting, cured in water at $20^{\circ} \mathrm{C}$ for 28 days. The mix proportions of the one composition investigated in this study and mechanical properties are given in Table 2 .

Table 2. Compositions of BCC.

\begin{tabular}{|c|l|}
\hline Constituents $\left.\mathbf{( k g} / \mathbf{m}^{3}\right)$ & BCC \\
\hline Coarse aggregate, $12-20 \mathrm{~mm}$ & 561.2 \\
\hline
\end{tabular}

\begin{tabular}{|c|c|}
\hline Medium aggregate, $4-12 \mathrm{~mm}$ & 432 \\
\hline Sand, $0-4 \mathrm{~mm}$ & 867.8 \\
\hline Cement H.P.C.C. & 242.9 \\
\hline Egyptian mix & 104.1 \\
\hline Water & 166.6 \\
\hline Water-to-binder ratio (W/B) & 0.48 \\
\hline \multicolumn{2}{|c|}{ Mechanical properties for $\mathrm{BCC}$} \\
\hline $\begin{array}{l}\text { 28-day compressive strength } \\
(\mathrm{MPa})\end{array}$ & 79 \\
\hline
\end{tabular}

\subsection{Test procedures on steel}

\subsubsection{Preparation of anticorrosive coating formulations}

Egyptian mix was impregnated in one concentrations of cobalt acetate, zinc acetate and both mixed together in the ratios of $2 \mathrm{Zn} \cdot 1 \mathrm{Co}$ is basically alumino-silicate, precipitating cobalt and zinc acetate on its surface make it possible for these species to react with the alumina in Egyptian mix to form blue cobalt aluminate and green zinc aluminate, since the green colour is predominant in the mixed pigments this indicates that zinc aluminate is the predominant phase that was formed.

After 2-4h of soaking in the different acetate solutions, the paste was filtered through buchner funnel then calcined at $800-900 \circ \mathrm{C}$; the ramp was set at $20 \circ \mathrm{C} / \mathrm{min}$. After calcinations, grinding of the pigment was done. Co aluminate/ Egyptian mix, zinc aluminate/ Egyptian mix were prepared in micronized.

The reaction takes place as follows:

$$
\begin{aligned}
& \mathrm{X}\left(\mathrm{CH}_{3} \mathrm{COO}\right) 2+\mathrm{H}_{2} \mathrm{O} \rightarrow \mathrm{XOH}+2 \mathrm{CH}_{3} \mathrm{COOH}(1) \\
& \mathrm{XOH}+\mathrm{Al}_{2} \mathrm{O}_{3} \rightarrow \mathrm{XO} \cdot \mathrm{Al}_{2} \mathrm{O}_{3}(2)
\end{aligned}
$$

where $\mathrm{X}$ is $\mathrm{Co}, \mathrm{Zn}$ or $\mathrm{Co} \cdot \mathrm{Zn}$

The prepared pigments were tested in 2 coating formulations. These coating formulations contain, micronized $2 \mathrm{Zn} \cdot 1 \mathrm{Co}$ aluminate/ Egyptian mix (KCW) and zinc phosphate coating (ZPC). Coating formulations are represented in Table 3.

Table 3. Coating formulations of $\mathrm{KCW}$ with medium oil alkyd resin and zinc phosphate coating.

\begin{tabular}{|c|c|c|}
\hline $\begin{array}{c}\text { Ingredients/coating } \\
\text { numbers }\end{array}$ & KCW & ZPC \\
\hline M. alkyd resin & 64.76 & - \\
\hline $\mathrm{Fe}_{2} \mathrm{O}_{3}$ & 21.18 & - \\
\hline $\mathrm{TiO}_{2}$ & 3.56 & - \\
\hline $\mathrm{ZnO}$ & - & 11 \\
\hline $2 \mathrm{Zn} \cdot 1 \mathrm{Co}$ aluminate/ Eg.mix & 4.28 & - \\
\hline $\mathrm{HNO}_{3}$ & - & 11 \\
\hline $\mathrm{H}_{3} \mathrm{PO}_{4}$ & - & 20 \\
\hline
\end{tabular}




\subsubsection{Test procedures on reinforced steel samples embedded in concrete.}

The tests concerns the carbon steel samples after treated by $\mathrm{KCW}$ embedded in $\mathrm{BCC}$ concrete (water/cement = $0.48)$. The $\mathrm{BCC}$ concrete $(\mathrm{BCC}+\mathrm{KCW})$ were immersed in a saturated calcium hydroxide and sea water. They were cylinders of $50 \mathrm{~mm}$ diameter and $100 \mathrm{~mm}$ height (figure 1). After mixing water, cement, aggregate and sand, the paste produced was poured into moulding in which carbon steel was placed according to its longitudinal axis. The samples were compacted then dried in air for 28days. After the samples were removed from the moulding, an epoxy resin coating was applied to the lower face of the sample to ensure the infiltration of the solution only through the lateral surface.

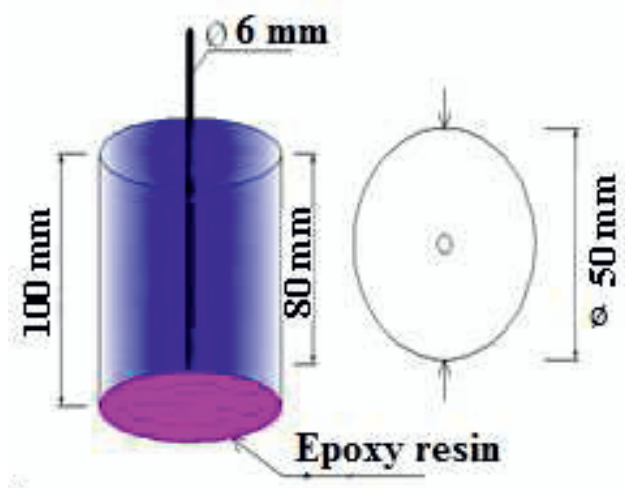

Fig. 1. Reinforced concrete specimen.

\subsubsection{Chemical condition simulating pore solution tests}

The carbon steel samples after treatment by $\mathrm{KCW}$ were immersed in a saturated calcium hydroxide $\mathrm{Ca}(\mathrm{OH})_{2}(\mathrm{~mol} / \mathrm{l}), \mathrm{NaOH}(0.001 \mathrm{~mol} / 1), \mathrm{KOH}(0.001 \mathrm{~mol} / \mathrm{l})$, to simulate the aqueous alkaline content of the (noncarbonated) concrete pore solution, with an approximate $\mathrm{pH}$ of 13. at ambient temperature. A saturated calcium hydroxide solution (noted S1) [5]. Mediterranean Sea water was introduced in S2.

\subsubsection{SEM/EDAK analysis}

Energy-dispersive X-ray analysis technique, and scanning electron microscopy (EDAK), micro-analyzer electron probe, was used in this work to estimate the particle shapes and to determine the elements deposited on kaolin surface to estimate the formation of the core-shell pigments

\section{Corrosion behaviour in synthetic pore solution and sea water}

3.1. Results of Carbon Steel Immersed in Synthetic Solutions Emulating Concrete after Coating.

\subsubsection{Open circuit potential.}

Figure 2 shows the open circuit potential (also referred to the rest potentials) test obtained from linear polarizaton tests for carbon steel samples immersed in synthetic concrete pore solutions S1 as after 1 hour, until 8 days of immersion. Each point in this figure is the average of two points. At the first hours of the addition of inhibitors the rest potentials $\mathrm{E}_{\mathrm{OC}}$ are respectively around $-200 \mathrm{mV}$ for the $\mathrm{S} 1+\mathrm{KCW},-360$ for $\mathrm{S} 1+\mathrm{BCC}+\mathrm{KCW}$ in comparison with reference steel without coating and $-300 \mathrm{mV}$ for $\mathrm{ZPC}$.

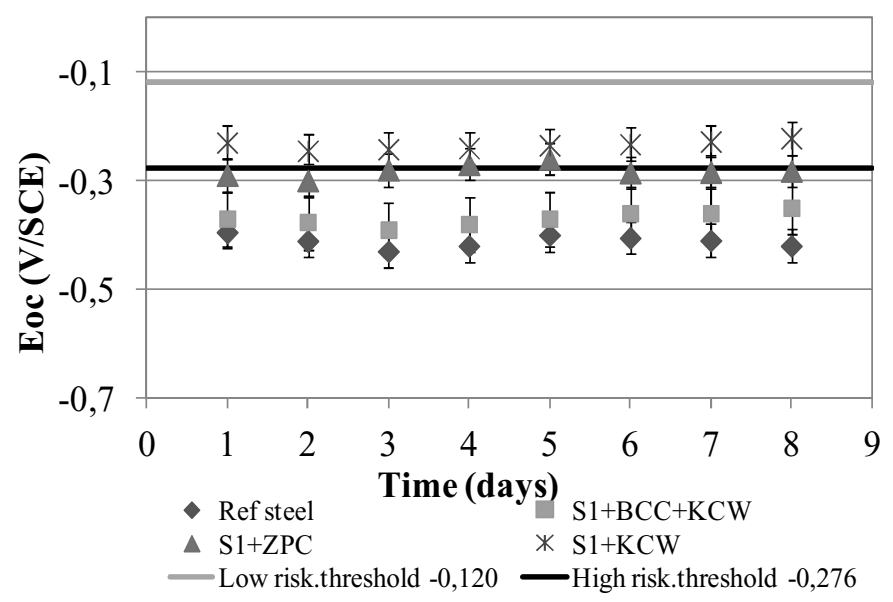

Fig. 2. Open Circuit Potential $\left(\mathrm{E}_{\mathrm{OC}}\right)$ of Carbon Steel samples immersed in S1 with and without inhibitors.

Guidance for interpretation of results is given in the ASTM standard C876-99 and is summarized in Table 4. The systems showing potentials lesser negative than-276 $\mathrm{mV}$ versus $\mathrm{SCE}$ are treated as passive systems and systems showing more negative than $-276 \mathrm{mV}$ versus SCE are treated as active. Thus, the rebars in $\mathrm{S} 1+\mathrm{KCW}$ are probably passive where as an active corrosion probably takes place on the rebars in Ref without coating and with $\mathrm{BCC}+\mathrm{KCW}$. The rest potentials increase with time. These results indicate adsorption of a KCW film on the iron surface which leads to a slowdown of the corrosion probability after the inhibitor addition.

Table 4. ASTM C876-99 criteria for corrosion of steel in concrete using different standard half-cells.

\begin{tabular}{|c|c|}
\hline Calomel & Corrosion condition \\
\hline$>-0.12 \mathrm{~V}$ & Low $((10 \%)$ risk of corrosion $)$ \\
\hline-0.12 to $-0.276 \mathrm{~V}$ & Intermediate corrosion risk \\
\hline$<-0.276 \mathrm{~V}$ & High $((>90 \%)$ risk of corrosion $))$ \\
\hline$<-0.426 \mathrm{~V}$ & Severe corrosion \\
\hline
\end{tabular}




\subsubsection{Corrosion current evolution.}

The corrosion currents obtained from applying cyclic polarization curves for $\mathrm{S} 1+\mathrm{KCW}, \mathrm{S} 1+\mathrm{ZPC}$ and $\mathrm{S} 1+\mathrm{BCC}+\mathrm{KCW}$ are illustrated in Figure 3. According to RILEM studies [6], 4 ranges of corrosion activity can be distinguished from negligible, to weak, to moderate and up to high Table 5. Each point of the corrosion current in this figure is the average of two points. After addition of $\mathrm{KCW}$, the data shows lower corrosion currents with time and after 8 days the corrosion current range is from 0.5 to $0.8 \mu \mathrm{A} / \mathrm{cm}^{2}$ for $\mathrm{S} 1+\mathrm{KCW}, \mathrm{S} 1+\mathrm{ZPC}$ respectively. For rebar $\mathrm{S} 1+\mathrm{BCC}+\mathrm{KCW}$, corrosion activity after 8 days is $\left(2.5 \mu \mathrm{A} / \mathrm{cm}^{2}\right)$. In cases, $\mathrm{S} 1+\mathrm{KCW}$, $\mathrm{S} 1+\mathrm{ZPC}$, the corrosion activity is constant with time. For Ref without coating and $\mathrm{BCC}+\mathrm{KCW}$ the current is more than $2 \mu \mathrm{A} / \mathrm{cm}^{2}$ corresponding to high rate corrosion. So the corrosion process is probably slowed down but not stopped. The order of Icorr from high to weak is: Ref $>\mathrm{S} 1+\mathrm{BCC}+\mathrm{KCW}>$ $\mathrm{S} 1+\mathrm{ZPC}>\mathrm{S} 1+\mathrm{KCW}$.

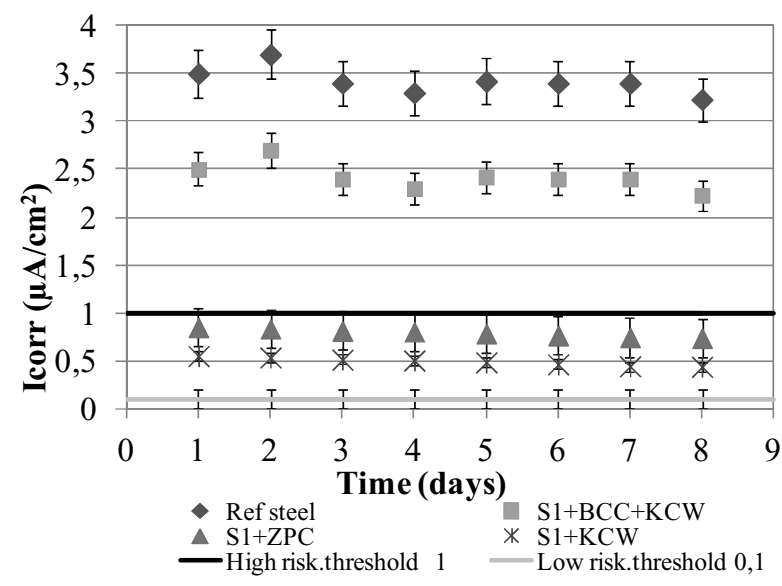

Fig. 3. Corrosion Current Density (icorr) of Carbon Steel samples immersed in S1 with and without coating.

Table 5. Typical corrosion rates for steel in concrete.

\begin{tabular}{|c|l|}
\hline Rate of corrosion & Current density $\operatorname{Icorr}\left(\boldsymbol{\mu} \mathbf{A} / \mathbf{c m}^{2}\right)$ \\
\hline Very high & $10-100$ \\
\hline High & $1-10$ \\
\hline Low/moderate & $0.1-1$ \\
\hline Passive & $<0.1$ \\
\hline
\end{tabular}

\subsubsection{EIS measurements in pore solution.}

The electrical parameters $\left(\mathrm{C}_{\mathrm{dl}}, \mathrm{R}_{\mathrm{ct}}\right)$ obtained through fitting EIS data, using the electric equivalent circuit $\mathrm{R}(\mathrm{QR})$ and $\mathrm{R}_{\mathrm{el}}+\mathrm{Cf} /\left(\mathrm{R}_{\mathrm{f}}+\mathrm{Cdl} / \mathrm{Rct}\right)$, are listed in (Table 6). EC-Lab software was used in data fitting. The mathematical method used was Levenberg- Marquardt method. Figure 4 shows a Nyquist plot of the impedance of carbon steel samples immersed in synthetic concrete pore solutions S1 after 1 hour, until 8 days of immersion. It can be noticed that the low frequency portion of the impedance spectra (on the right hand side) increases with presence of inhibitor in the solution as a sign of passivity does not break down. Figure 4 shows the main conclusions for all types of coating, the order of inhibition is: $\mathrm{S} 1+\mathrm{KCW}>\mathrm{S} 1+\mathrm{ZPC}$ $>\mathrm{S} 1+\mathrm{BCC}+\mathrm{KWC}>$ Ref according to the values of Rct. Basically, the passive film has a high resistivity with $\mathrm{KCW}$; however, it decreased with reference specimens in the solution S1. The coating layer of iron oxides/hydroxides surface film seems to cover the entire surface blocking the active sites and the total impedance of the system increases continuously.

Table 6. Electrical parameters for treated and untreated carbon steel immersed in S1 solution obtained through fitting EIS data.

\begin{tabular}{|l|c|c|c|c|}
\hline Sample & $\begin{array}{l}\mathrm{C}_{\mathrm{f}} \\
\mu \mathrm{f} / \mathrm{cm}^{2}\end{array}$ & $\begin{array}{l}\mathrm{Rct} \\
\mathrm{k} \Omega . \mathrm{cm}^{2}\end{array}$ & $\begin{array}{l}\mathrm{R}_{\mathrm{f}} \\
\mathrm{k} \Omega . \mathrm{cm}^{2}\end{array}$ & $\begin{array}{l}\mathrm{Cdl} \\
\mu \mathrm{F} / \mathrm{cm}^{2}\end{array}$ \\
\hline Ref. & - & 301 & - & 24.12 \\
\hline S1+BCC+KCW & 2.11 & 402 & 0.864 & 6.33 \\
\hline S1+ZPC & 2.42 & 1585 & 2.17 & 4.24 \\
\hline S1+KCW & 1.71 & 1111 & 4.45 & 2.17 \\
\hline
\end{tabular}

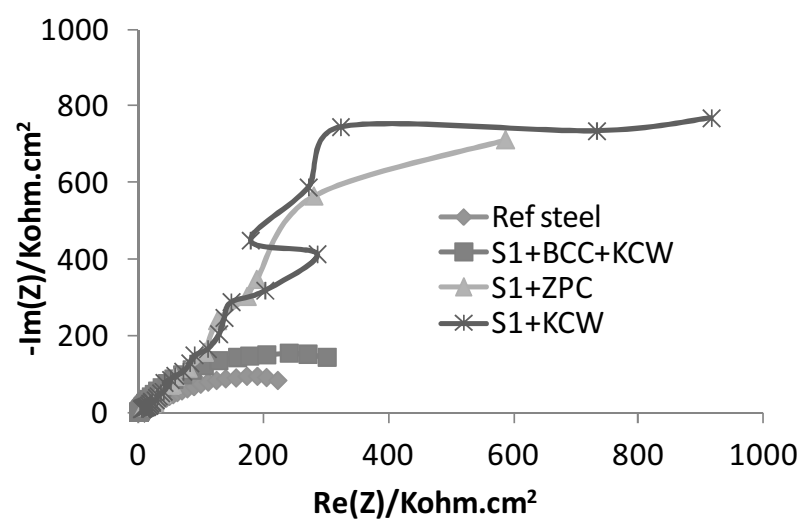

Fig. 4. Nyquist plots for steel without and with coating KCW, $\mathrm{ZPC}$ and $\mathrm{BCC}+\mathrm{KCW}$ after 8 days in $\mathrm{S} 1$.

\subsubsection{Surface analysis with SEM}

Figure 5 show the morphology of the prepared coating using SEM. From the featured photos it can be seen that, the pigment particles have flower and platelet structures with high alignment on each other in case of $\mathrm{kcw}$. These plates provide a reinforcing effect reducing the water and gas permeability, and therefore imparting good anticorrosive properties and special appearance to the coating film when used in paint formulations [7]. In case of core-shell pigments another phase appeared on surface of $\mathrm{kcw}$ coarse particles showing the formation of the different phases or shells with their different structures, the more crowded surface was that of the coating. 


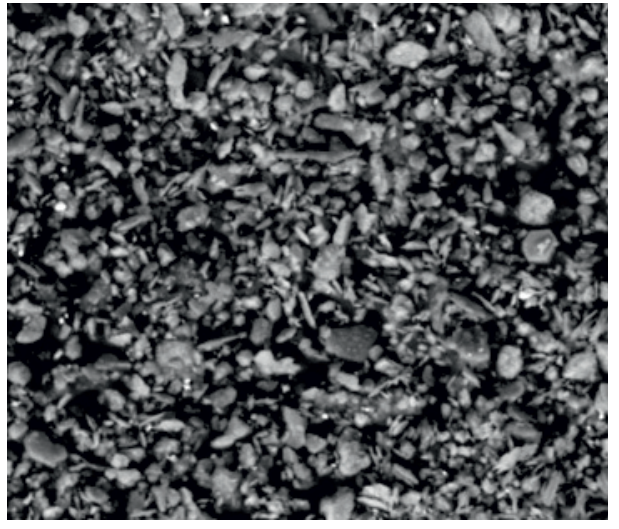

a. Eg.mix

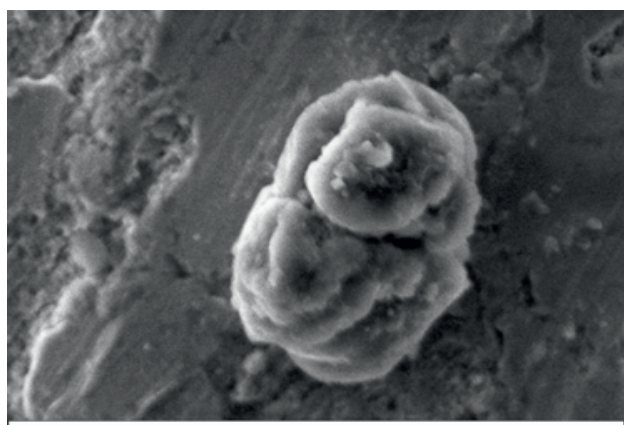

c.S1+ZPC

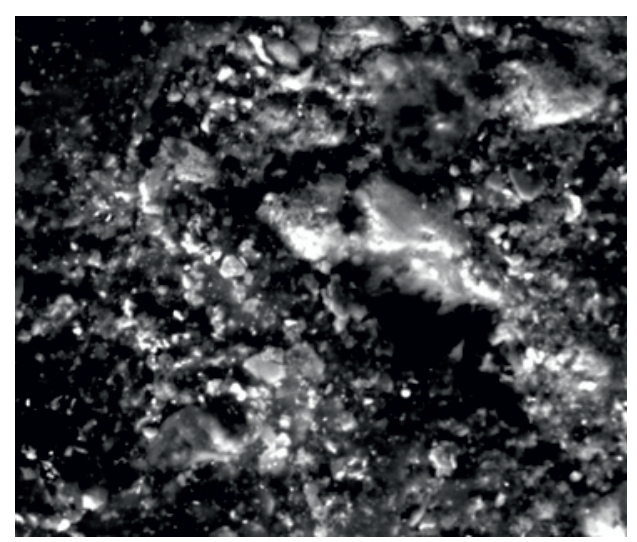

b.S1+BCC+KCW

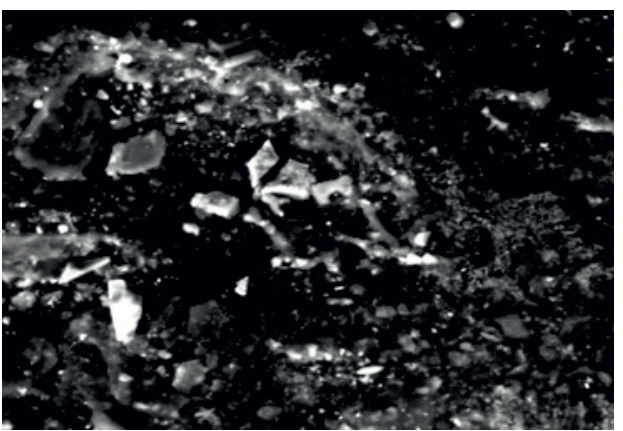

d.S $1+\mathrm{KCW}$

Fig. 5. SEM micrographs of: (a) Eg.mix, (b) Carbon steel in $(\mathrm{S} 1+\mathrm{BCC}+\mathrm{KCW})$, (c) Carbon steel in (S1+ZPC), and (d) Carbon steel in $(\mathrm{S} 1+\mathrm{KCW})$ at magnification $2000 \times$.

\subsection{Results of Carbon Steel Immersed in sea water under Chloride lon Attack after Coating.}

\subsubsection{Open circuit potential}

Figure 6 shows the open circuit potential in case of carbon steel Immersed in pore solution after coating under sea water. The rest potential value for Ref decreases significantly after 8 days (due to the presence of chloride). A drop in the corrosion potential was happened by other researchers as an indication of reaching the critical chloride limit [8]. For $\mathrm{S} 2+\mathrm{BCC}+\mathrm{KCW}$ and $\mathrm{S} 2+\mathrm{ZPC}$ the rest potential has approximately the same value and increases with time. This result due to two reasons: the first reason is the competition between chloride and the film of coating which leads to increase resistivity of the film the second reason is $\mathrm{kcw}$ completely reacted with the mixed oxide formed between zinc oxide and cobalt oxide, to form its crystalline completely cover the surface of steel, so the concentration of chloride required for initiation of corrosion is not enough.

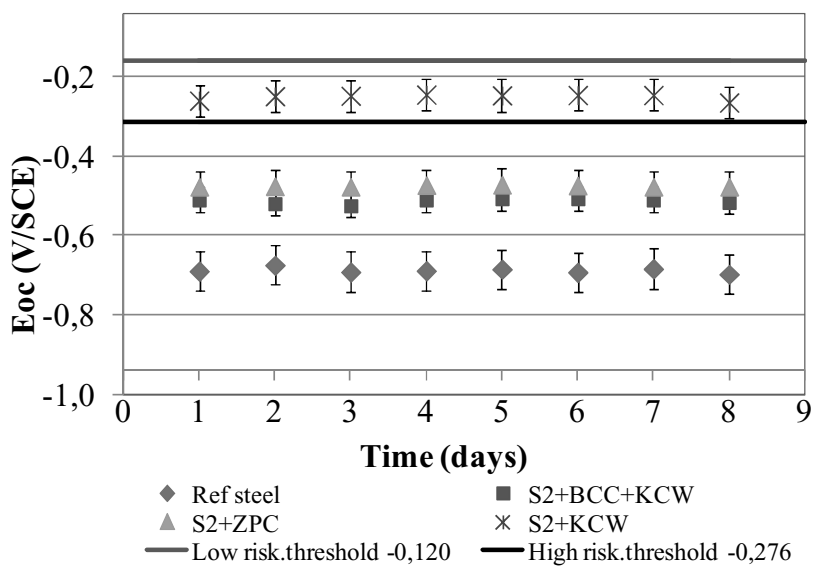

Fig. 6. Open Circuit Potential $\left(\mathrm{E}_{\mathrm{OC}}\right)$ of Carbon Steel samples immersed in $\mathrm{S} 2$.

\subsubsection{Corrosion current evolution.}

Figure 7 shows the corrosion current density (icorr) obtained from carbon steel samples immersed in S2. With time, the corrosion currents for $\mathrm{S} 2+\mathrm{KCW}$ remain low and closed to values obtained with no chloride. The previous result indicates that 
$\mathrm{KCW}$ not affected by the presence of chloride and this due to that nitrite does not incorporate into the passive film, but reacts with the anodic corrosion products in the early stage competing with the chloride ions and hydroxide ions. It helps to repair the flaws, which are caused by chloride dissolution of the oxide film to the soluble chloro complexes of iron [9]. But S2+ZPC and $\mathrm{S} 2+\mathrm{BCC}+\mathrm{KCW}$ show corrosion current which is constant with time and ranging from 3 and $4 \mu \mathrm{A} / \mathrm{cm}^{2}$ for $\mathrm{ZPC}$ and $\mathrm{BCC}+\mathrm{KCW}$ respectively at 8 days, indicating a lower corrosion activity of the rebars. Each sample needs enough time to whether develop its passivation layer or actively corrode. For Ref., the corrosion currents of rebars increase slightly with time because of the corrosion products.

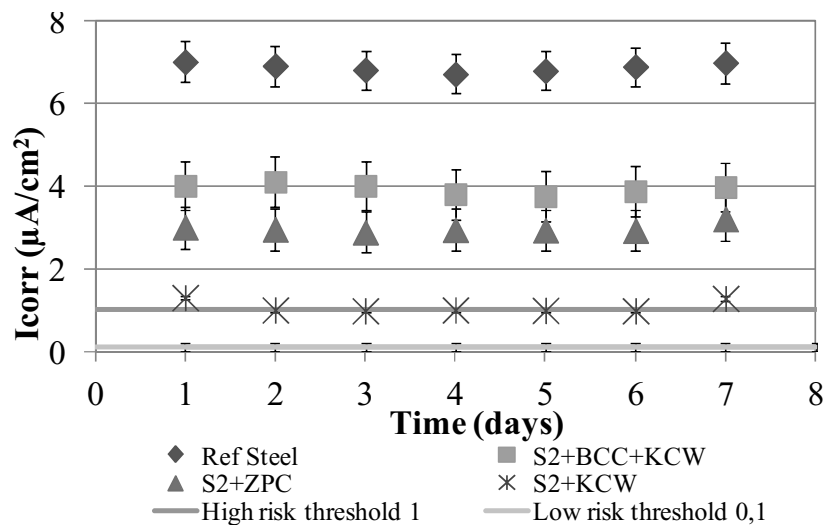

Fig. 7. Corrosion Current Density (icorr) of Carbon Steel samples immersed in S2.

\subsubsection{EIS measurements in pore solution.}

The electrical parameters are listed in (Table 7) at 8 days. EIS data for $\mathrm{S} 2$ containing $\mathrm{KCW}, \mathrm{ZPC}$ and $\mathrm{BCC}+\mathrm{KCW}$ aged 8 days in the same aggressive solution. This is data due to a competition between the formation and local destruction of the film obtained by the slow inhibitor dissolution. This classical corrosion mechanism leads to the diminution of Rct and to the increase of the double layer capacitance $\mathrm{C}_{\mathrm{dl}}$ while $\mathrm{R}_{\mathrm{f}}$ increases in comparison with $\mathrm{S} 1$. This evolution corresponds to the electrolyte diffusion into the film pores. Figure 8 shows the main conclusions for all types of coating, the order of inhibition is: $\mathrm{S} 2+\mathrm{KCW}>\mathrm{S} 2+\mathrm{ZPC}>\mathrm{S} 2+\mathrm{BCC}+\mathrm{KCW}>\mathrm{Ref}$ according to the values of Rct.

Table 7. Electrical parameters for treated and untreated carbon steel immersed in S2 solution obtained through fitting EIS data.

\begin{tabular}{|l|c|c|c|c|}
\hline Sample & $\begin{array}{l}\mathrm{C}_{\mathrm{f}} \\
\mu \mathrm{f} / \mathrm{cm}^{2}\end{array}$ & $\begin{array}{l}\mathrm{Rct} \\
\mathrm{k} \Omega . \mathrm{cm}^{2}\end{array}$ & $\begin{array}{l}\mathrm{R}_{\mathrm{f}} \\
\mathrm{k} \Omega . \mathrm{cm}^{2}\end{array}$ & $\begin{array}{l}\mathrm{Cdl} \\
\mu \mathrm{F} / \mathrm{cm}^{2}\end{array}$ \\
\hline Ref. & - & 251 & - & 33.02 \\
\hline S2+BCC+KCW & 6.42 & 362 & 0.66 & 8.22 \\
\hline S2+ZPC & 4.22 & 385 & 1.09 & 6.13 \\
\hline S2+KCW & 2.65 & 651 & 1.45 & 3.65 \\
\hline
\end{tabular}

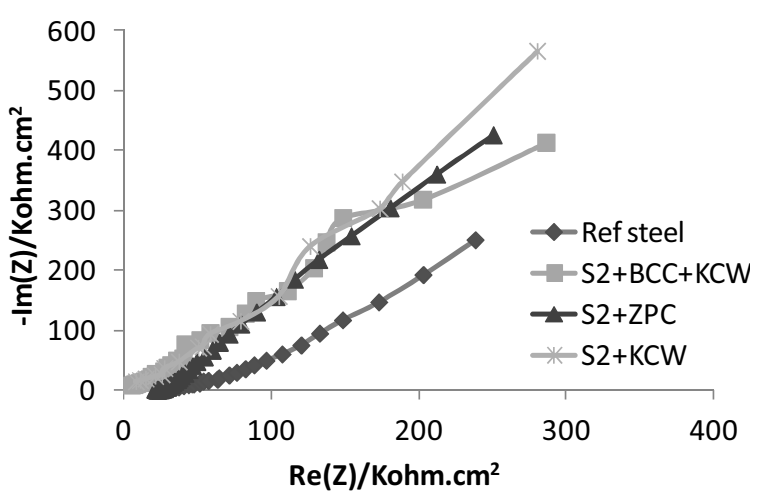

Fig. 8. Nyquist plots for steel without and with coating KCW, $\mathrm{ZPC}$ and $\mathrm{BCC}+\mathrm{KCW}$ after 8 days in $\mathrm{S} 2$.

\subsubsection{Cyclic polarization curve.}

Figure 9 represent the potentiodynamic polarization curves of steel in $\mathrm{S} 2$ solution without and with $\mathrm{KCW}$, $\mathrm{ZPC}$ and $\mathrm{BCC}+\mathrm{KCW}$. A higher significant potential shift is observed between S2 with coating and the S2 without coating. The increase of the passive current density for the film resistance is suggesting the presence of a protective homogeneous layer on the steel surface. S2+BCC lead to the anodic formation of a passive layer which contributes to the decrease of chloride aggressiveness; this is due to that $\mathrm{KCW}$ gives better build film texture with improved properties.

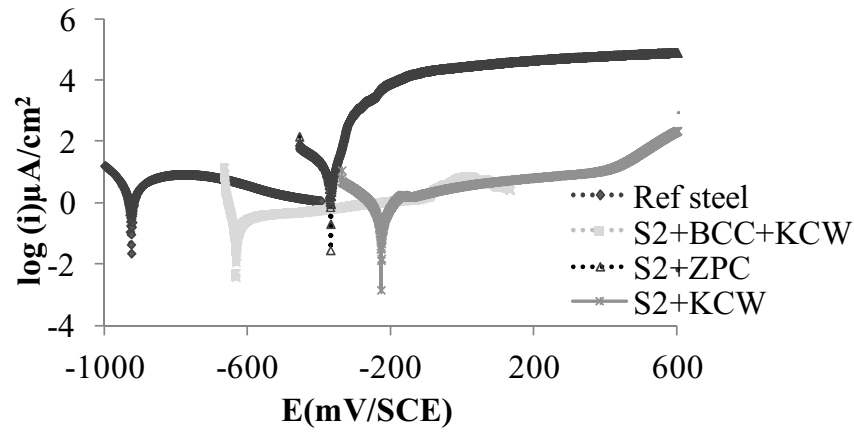

Fig. 9. Cyclic polarization curve of carbon steel after 8 days of immersion in sea water S2 with coating.

\section{Conclusions}

New coating were prepared in this paper based on the reaction of cobalt and zinc species with the alumina found naturally in Egyptian mix (kaolin and ceramic waste) forming new aluminate coating with intense color and concomitant savings.

In alkaline solution with or without chloride, the $\mathrm{KCW}$ steel sample is more resistant than carbon steel alone and causing passivation of steel in concrete. Thus, a dense and protective layer is formed. 
$\mathrm{BCC}+\mathrm{KCW}$ give the good results in mechanical properties and the same trend with pore concrete solutions measured, however, with a chloride ions solution, $\mathrm{KCW}$ in sea water formed passive layer contributes to the decrease of chloride aggressiveness.

\section{References}

1. N.Mohamed. Ahmed, H. Tawfik, and E. Youssef. Progress in Organic Coatings 73 (2012) 76-87.

2. D. Visinescu, C. Paraschiv, A. Ianculescu, B. Jurca, B. Vasile, O. Carp, Dyes and Pigments 87 (2) (2010) 125-131.

3. N.M. Ahmed, Anticorrosion Methods and Materials 56 (1) (2009) 51-59.

4. D.Fernández-Osorio,E.Hernández-Mendoza, Pineda-Villanueva, Nanotech-nology 1 (2010) $448-451$

5. F .Simescu. H.Idrissi, Corrosion Science. vol. 51, $\mathrm{n}^{\circ} 4(2009)$, p. 833-840.

6. C. Andrade, A. Alonso, RILEM TC 154-EMC: Electrochemical Techniques for Measuring Metallic Corrosion - Recommendations, Materials and Structures, Vol. 37, $\mathrm{n}^{\circ}$, (2004), pp.623643.

7. M. Zawadzki, Solid State Sciences 8 (1) (2006) 14-18.

8. Li, L., and Sagues, A. A. Corrosion, 57(1), 19. (2001).

9. B. El-Jazairi, and Berke N.S., Elsevier Science Publishers Ltd ., Wishaw, Warwickshire, UK. (1992). 